\title{
A DINÂMICA DO SISTEMA FINANCEIRO GLOBAL E SUAS REPERCUSSÕES NA ECONOMIA REAL: UMA ANÁLISE DAS CONSEQUÊNCIAS PARA O BRASIL DA CRISE NORTE-AMERICANA PRONUNCIADA EM 2008
}

\section{Luana Maria Lyra Carreras}

Graduada em Tecnologia em Comércio Exterior pelo Instituto Federal de Educação, Ciência e Tecnologia do Rio Grande do Norte. Graduanda do curso de Direito pela UFRN.

E-mail: luanacarreras@ hotmail.com.

Elisângela Cabral de Meireles

Graduada em Ciências Econômicas-UFRN, esp. em Economia Regional, Comércio Exterior e Globalização-UFRN, mestre em Administração (Gestão e Políticas Públicas) UFRN , Professora do IFRN (Comércio Exterior e Economia) e Professora Orientadora da Base de Pesquisa "Análise do Mercado Exportador do Rio Grande do Norte (IFRN).

E-mail- elisangela@ cefetrn.br

\section{RESUMO}

No campo econômico-financeiro, atuam as crises financeiras e econômicas. $\mathrm{O}$ trabalho enfatiza as consequiências da crise americana de 2008 para o Brasil e quais as políticas econômicas adotadas pelo país para contornar os impactos causados em nível nacional. Nesse contexto, a pesquisa teve como objetivo geral compreender como a dinâmica do sistema financeiro pode vir a interferir na economia real dos países, dando ênfase ao cenário de mudanças instauradas no Brasil pela crise norte-americana em 2008, e, para lograr esse êxito, utilizou-se dos objetivos específicos: entendimento de como a realidade financeira de um país pode intervir na economia de outros países; correlação entre sistema financeiro e economia real; visão geral da realidade econômica global atual; exame da intervenção estatal na economia dos seus respectivos países, no intento de contornar os problemas financeiros empresariais e as conseqüências destes; discussão da importância das fusões bancárias para o Brasil no presente cenário internacional; relação entre a crise financeira com o comércio internacional e por fim, análise das políticas econômicas adotadas pelo governo brasileiro em resposta às conseqüências da crise internacional para o país. A metodologia utilizada foi, quanto aos fins, exploratória explicativa e, com relação aos meios, bibliográfica, utilizando-se autores a exemplo de KRUGMAN (2009) e WOLF (2009). Como resultados e conclusões, verifica-se que a presença de crises são comuns e corriqueiras no Sistema Capitalista, assim como as recessões e intervalos de crescimento são sintomas normais do ciclo econômico. Cabe aos países se manterem em alerta, para que as conseqüências das crises são sejam muito maléficas. Por fim, vimos que o Brasil tem se saído bem, por meio da adoção de políticas monetária, tributária, fiscal, comercial e desenvolvimentista.

PALAVRAS-CHAVE: Crise Americana de 2008, sistema financeiro, economia real, Brasil.

\footnotetext{
THE DYNAMICS OF THE GLOBAL FINANCIAL SYSTEM AND YOURS REPERCUSSIONS IN THE REAL ECONOMY: A ANALYSES OF THE CONSEQUENCES OF AMERICAN CRISIS PRONOUNCED IN 2008 TO BRAZIL
} 


\begin{abstract}
In the economic and financial field, we can see the financial and economic crises. This monograph emphasizes the consequences of the recent American to Brazil and which are the economic policies adopted by our country to contour the impacts caused in a national level. Inside this context, the research had as the main object comprehend how the dynamics of the financial system can interfere in the real economy of the countries, emphasizing the scenery of changes found in Brazil by the North-American crisis in 2008, and, to get this goal, were seeing the following specific objects: understanding of how the financial reality of one country can interfere in the economy of others countries; correspondence between financial system and real economy; general view of current global economic reality; exam of the governmental intervention in theirs respective economies, in the intent of contour the financial problems of the companies; discussion of the importance of fusion among banks to Brazil in this current international scenery; relation between American crisis with the foreign trade and, to conclude, the analysis of the economic policies adopted by the brazilian government as an answer to the international crisis consequences to Brazil. The scientific methodology adopted was, in relation to the finalities, exploratory and explanatory and, about the resources, it was bibliographic, by the use of books of, for example, KRUGMAN (2009) and WOLF (2009). As results, we conclude that the crises are ordinaries in the Capitalist System, like the recessions and gaps of development are normal symptoms of the economic cycle. So, we can say that it is an owe to the countries to keep in alert to avoid very harmful crises consequences. In a last point, we see that Brazil has getting to minimize the impacts by the use of monetary, tributary, fiscal, commercial and developmentist policies.
\end{abstract}

KEY-WORDS: American Crisis of 2008, financial system, real economy, Brazil.

\title{
A DINÂMICA DO SISTEMA FINANCEIRO GLOBAL E SUAS REPERCUSSÕES NA ECONOMIA REAL: UMA ANÁLISE DAS CONSEQUÊNCIAS PARA O BRASIL DA CRISE NORTE-AMERICANA PRONUNCIADA EM 2008
}

\section{INTRODUÇÃO}

O objetivo geral da presente pesquisa foi compreender como a dinâmica do sistema financeiro pode vir a interferir na economia real dos países, dando ênfase ao cenário de mudanças instauradas no Brasil pela crise norte-americana em 2008.

Sendo assim, constatou-se que o atual panorama da economia global caracteriza-se por uma situação de grande instabilidade, marcada por constantes oscilações nas principais bolsas de valores do mundo (na BOVESPA e na Bolsa de Nova Iorque, por exemplo, houve sucessivas quedas consideráveis, como há muitos anos não se via); quebra de instituições consideradas altamente representativas dentro do seu setor; falências; demissões; uma maior intervenção do Estado na economia, injetando bilhões de dólares na tentativa de contornar a recessão; diminuição de crédito, entre outros.

Como resultado do comportamento dessas e de outras variáveis diretamente relacionadas ao sistema financeiro mundial, verificaram-se mudanças na dinâmica da economia real dos países, que acabaram por serem afetados, mesmo que de modo diverso e em intensidades diferentes. 
Nesse contexto, a Economia do Brasil também foi atingida.

Segundo o presidente do Banco Central do Brasil, os avanços na economia brasileira demonstram um ciclo de crescimento sustentável e de investimentos, onde a atuação das instituições financeiras é essencial para tornar realidade tal perspectiva.

Afirma ainda que, no Brasil, o sistema financeiro provou sua resiliência, absorvendo os choques dos anos 90 e dos primeiros anos do século XXI e que, ao mesmo tempo, a estabilização econômica e a abertura externa, com a conseqüente influência sobre a concorrência e o crescente fluxo de capitais externos, resultaram em novas oportunidades e desafios para um sistema financeiro eficiente, capitalizado, rentável e solvente.

Com relação à crescente integração internacional, MEIRELES (2007) concorda que ela além de proporcionar a oferta de produtos e serviços financeiros globais, permite uma maior eficiência na alocação de capital, e que essa tendência deve se fortalecer, reduzindo custos operacionais e aproveitando sinergias. A integração, contudo, facilita a disseminação de choques financeiros entre os países, requerendo que as autoridades adotem uma abordagem de regulação e supervisão integrada e consolidada.

Quanto à inserção do setor bancário nesse cenário, é interessante observar o ponto de vista de Fábio Barbosa, um dos diretores executivos da Febraban. Ele diz que cada vez mais se trabalha com a noção de interdependência e que, por isso, em vez de usar a expressão "setor bancário", que traz a idéia de compartimento, os executivos dizem "sistema financeiro", que amplia o conceito, inclui clientes, rede, mercados, segmentos, informação, tecnologia, controle, entidades representativas.

$\mathrm{Na}$ atualidade, as atenções têm-se voltado para os processos de aquisições bancárias, e principalmente da fusão entre Itaú e Unibanco, bem como das perspectivas de negociações entre Banco do Brasil, Caixa Econômica e Banco Votorantim.

A consolidação do setor financeiro traz consigo a questão da atuação da regulação no setor. Por isso, é muito importante estudar os dispositivos legais que dispõem sobre esses tipos de negociações, relacionando-os com aqueles que rezam sobre a concorrência e a ordem econômica e financeira do Brasil.

A facilidade com que as comunicações e as informações fluem pelo mundo está desafiando o conceito de independência e colocando o de interdependência. Estamos aliados com o momento que a sociedade está vivendo, talvez até puxando um pouco, mas não estamos desconectados. Não adianta ficar discutindo o que os bancos querem, precisa ver o que a indústria está dizendo, o que o comércio quer, e como é que nós vamos colocar tudo isso na mesa e discutir, porque o momento é de interdependência. Bancos fortes acontecem em economias fortes. (Barbosa, 2007)

Veremos que as diversas ações desempenhadas no âmbito do sistema financeiro, acabam por afetar a Economia Real, ou seja, os fenômenos econômicos mais paupáveis, diretamente relacionados aos produtos e serviços comercializados e utilizados por todos nós. 
O Brasil foi atingido pela Crise Financeira inicialmente pela contenção de crédito verificada em nível mundial. A partir desse "ataque", o Brasil começou a organizar uma linha de frente para combater os demais efeitos decorrentes desse declínio de crédito. Implantou, num primeiro momento, mudanças na política monetária, e posteriormente, na política tributária e, portanto, fiscal. Vem criando linhas de financiamento especiais, principalmente através da Caixa Econômica Federal e do BNDES, dentre outras medidas.

Diante desse contexto, o estudo se deu em torno dos seguintes objetivos específicos: entendimento de como a realidade financeira de um país pode intervir na economia de outros países; correlação entre sistema financeiro e economia real; visão geral da realidade econômica global atual; exame da intervenção estatal na economia dos seus respectivos países, no intento de contornar os problemas financeiros empresariais e as conseqüências destes; discussão da importância das fusões bancárias para o Brasil no presente cenário internacional; relação entre a crise financeira com o comércio internacional e por fím, análise das políticas econômicas ${ }^{1}$ adotadas pelo governo brasileiro em resposta às conseqüências da crise internacional para o país.

No tocante à metodologia, para a classificação da pesquisa, tomou-se como base a taxionomia apresentada por Vergara (1990), que a qualifica em relação a dois aspectos: quanto aos fins e quanto aos meios e conceitos trazidos por Gil (2002).

Quanto aos fins, a pesquisa foi inicialmente do tipo exploratória-explicativa, afirmando Gil que a pesquisa exploratória tem como objetivo proporcionar maior familiaridade com o problema, com vistas a torná-lo mais explícito ou a constituir hipóteses, podendo-se dizer ainda que estas pesquisas têm como objetivo principal o aprimoramento de idéias ou a descoberta de intuições. Seu planejamento é, portanto, bastante flexível, de modo que possibilita a consideração dos mais variados aspectos relativos ao fato estudado. "A pesquisa explicativa, por sua vez, tem como preocupação central identificar os fatores que determinam ou que contribuem para a ocorrência dos fenômenos. Esse é o tipo de pesquisa que mais aprofunda o conhecimento da realidade, porque explica o porquê das coisas" (GIL, 2002, pág. 42).

Com relação aos meios, tratou-se de pesquisa de cunho bibliográfico, por meio de consultas a livros, fontes de legislação brasileira, revistas, jornais, sites e artigos científicos.

O universo de pesquisa foi o sistema financeiro, com ênfase nas mudanças provocadas globalmente devidas a crise econômica americana, que se pronunciou em 2008.

Como amostras, foram consideradas principalmente as medidas econômicas adotadas pelo governo brasileiro, como resposta às alterações impostas pela crise americana ao sistema financeiro global.

\footnotetext{
${ }^{1}$ Compreende as ações executadas pelos agentes de política econômica, ou seja, pela Administração Pública Estatal e pelo Banco Central e internacionalmente por órgãos como o FMI e o Banco Mundial. Essas ações se concretizam através da utilização de instrumentos, que pode ser: política fiscal, política tributária, política monetária, política externa (por meio das políticas cambial e comercial) etc.
} 
Para analisar os dados, foram utilizados instrumentos de estatística descritiva, como gráficos e tabelas, já que consistem em ferramentas que possibilitam uma melhor visualização da distribuição dos dados numéricos, facilitando as análises pertinentes e correlações de variáveis e fatores.

Por fim, quanto ao encadeamento das informações pertinentes ao entendimento do tema do presente trabalho, optou-se pela evolução de idéias em quatro etapas.

No momento inicial partiu-se do conhecimento de definições de termos presentes na realidade do sistema financeiro, como o que são finanças, instituições financeiras, mercados financeiro e monetário etc; para o conhecimento da origem e evolução do sistema financeiro nacional ( $\mathrm{SFN}$ ), com suas principais instituições: Banco do Brasil, SUMOC, BACEN, CMN, CVM, BM\&F etc.

Numa segunda etapa, ingressamos no campo das temidas crises financeiras, destacando aquelas mais recentes, como as crises mexicana, asiática e japonesa; para nos deter em seguida no foco principal: a crise financeira americana de 2008.

O terceiro momento foi reservado para se discutir a relação dos processos de integração entre empresas com a globalização atual, enfatizando as fusões e aquisições na realidade do sistema bancário.

Por fim, depois de nos orientarmos com consistência nesse contexto do sistema financeiro, estamos aptos a discorrer sobre as principais medidas adotadas pelo Brasil em decorrência dos impactos da atual crise global sobre sua Economia, destacando seu cenário macroeconômico, a disponibilidade de crédito, a questão do spread bancário, a situação da indústria nacional, a política tributária pós-crise e o balanço de pagamentos - em especial quanto às exportações e importações.

Concluindo a pesquisa, enfim, são feitas considerações sobre as questões econômicas e financeiras abordadas, correlacionando os seus aspectos diversos com os impactos sofridos pela Economia do Brasil, analisando-se, por fim, os caminhos que vem sendo escolhidos pelo país em busca da sustentabilidade, crescimento e desenvolvimento econômico.

\section{A DINÂMICA DO SISTEMA FINANCEIRO}

\section{Aspectos importantes do sistema financeiro em caráter mundial}

Em finanças, denomina-se genericamente por sistema financeiro, qualquer estrutura que tenha como objetivo descrever a circulação do dinheiro em determinada organização, a qual engloba a obtenção de recursos e sua aplicação.

Por sua vez, podemos definir finanças, de acordo com Gitman (2004), como sendo a arte e a ciência da gestão do dinheiro. A área de finanças preocupa-se com os processos, as instituições, os mercados e os instrumentos associados à transferência de dinheiro entre indivíduos, empresas e, ou órgãos governamentais. 
Instuições financeiras, nas palavras de Gitman (2004), atuam como intermediárias, promovendo a canalização das poupanças de indivíduos, empresas e órgãos de governo para empréstimos ou aplicações. Essas instituições são obrigadas pelo governo a atuar dentro de diretrizes regulamentadoras. Gitman (2004) aponta como as principais instituições da economia americana os bancos comerciais, as associações de poupança e empréstimos, as cooperativas de crédito, as caixas econômicas, as companhias de seguro, os fundos de pensão e os fundos de investimento.

Já com relação aos mercados financeiros, Gitman (2004) os define como fóruns nos quais fornecedores e demandantes de fundos podem transacionar diretamente. Os dois mercados financeiros básicos são o mercado monetário (onde ocorrem transações que envolvem instrumentos de dívida de curto prazo - fundos com prazo de vencimento máximo de um ano, ou títulos negociáveis) e o mercado de capitais (aquele destinado a negociações de títulos de longo prazo, ou seja, obrigações e ações).

O mercado monetário é responsável, na maioria das vezes, por transações que envolvem títulos negociáveis, ou seja, instrumentos de dívida de curto prazo, tais como letras do Tesouro, notas promissórias comerciais e certificados negociáveis de depósito emitidos por órgãos governamentais, empresas e instituições financeiras, respectivamente.

"O equivalente internacional do mercado monetário doméstico é o mercado de euromoedas, caracterizado por depósitos bancários de curto prazo em dólares ou outra moeda facilmente conversível. Historicamente, Londres é o centro do mercado de euromoedas, mas ele evoluiu para um mercado verdadeiramente global". (GITMAN, 2004)

O mercado de capitais permite a realização de transações entre fornecedores e demandantes de fundos de longo prazo. Inclui emissões de títulos de empresas e órgãos governamentais. Gitman (2004) por analogia diz que a espinha dorsal desse mercado é formada pelas várias bolsas de valores, onde os principais títulos negociados são obrigações (dívidas de longo prazo, que podem ser utilizadas por empresas e órgãos governamentais para levantar volumes substanciais de recursos, geralmente junto a um grupo de fornecedores) e ações ordinárias e preferenciais (títulos de participação acionária ou propriedade).

Finalmente, o mercado internacional de ações permite às empresas vender lotes de ações a investidores de vários países ao mesmo tempo. Esse mercado permiti-lhes captar volumes maiores de capital do que poderiam obter em qualquer mercado nacional isoladamente. As vendas de ações nesse mercado têm se mostrado indispensáveis para os governos que privatizaram empresas estatais.

A relação entre instituições e mercados, continua o autor supracitado, se dá na medida em que aquelas participam ativamente dos mercados financeiros, como fornecedoras ou demandantes de fundos.

\section{Sistema financeiro do Brasil}

Primeiramente, é importante tratar da origem e evolução do sistema financeiro brasileiro, para então discorrer sobre as principais instituições que o compõe. 
Pode-se dizer que o sistema financeiro brasileiro teve início com a vinda da Família Real portuguesa, em 1808, quando foi criado o Banco do Brasil. Com o tempo, novas instituições foram surgindo, como a Inspetoria Geral dos Bancos (1920), a Câmara de Compensação do Rio de Janeiro (1921) e de São Paulo (1932), dentre outros bancos e instituições privadas e as Caixas Econômicas.

Alguns anos depois, já em 1945, é criada a Superintendência da Moeda e do Crédito (SUMOC), que em 1964 daria origem ao Banco Central do Brasil (BACEN). Nas décadas de 50 e 60, com a criação do BNDES, do Sistema Financeiro da Habitação, do Banco Nacional da Habitação e do Conselho Monetário Nacional (CMN), o país passa por um novo ciclo econômico e o sistema financeiro nacional passa a ser regulamentado através do Banco Central e do CMN, que tornam-se os principais orgãos do sistema.

Com a anuência do CMN e com o surgimento de bancos de investimento, a obtenção de recursos exteriores foi facilitada para as empresas, o que foi muito importante para o crescimento do Brasil, tendo em vista que a iniciativa fez gerar um considerável aumento de fluxo de capitais no país.

Na década de 70, são criados a Comissão de Valores Mobiliários (CVM), a qual facilita a obtenção de recursos pelas empresas - mais precisamente em 1976 - e o Sistema Especial de Liquidação e Custódia, em 1979, que passou a realizar a custódia e a liquidação de títulos públicos, como as Letras do Tesouro Nacional e as Obrigações Reajustáveis do Tesouro Nacional.

Em 1985, iniciou-se um processo de reordenamento financeiro governamental, o qual se estendeu até 1988, quando as funções de autoridade monetária foram transferidas progressivamente do Banco do Brasil para o Banco Central, enquanto as atividades atípicas exercidas por esse último, como as relacionadas ao fomento e à administração da dívida pública federal, foram transferidas para o Tesouro Nacional.

Com a instituição da Carta Magna, em 1988, o SFN passa a ser visto, em seu Título VII Da ordem econômica e financeira - Capítulo IV, art. 192, da seguinte forma:

O sistema financeiro nacional (SFN), estruturado de forma a promover o desenvolvimento equilibrado do País e a servir aos interesses da coletividade, em todas as partes que a compõem, abrangendo as cooperativas de crédito, será regulado por leis complementares que disporão, inclusive, sobre a participação do capital estrangeiro nas instituições que o integram. (CONSTITUIÇÃO FEDERAL, 1988)

Em 1996, é criado o Copom, ligado ao Bacen, que estabelece as diretrizes da política monetária, como a taxa SELIC.

Após esse aparato histórico, partamos ao conhecimento das principais instituições do sistema financeiro nacional. $\mathrm{O}$ sistema financeiro nacional (SFN) é formado por um conjunto de instituições financeiras voltadas para a gestão da política monetária do governo federal, sendo formado por entidades supervisoras e por operadores que atuam no mercado nacional, e orientado por três órgãos normativos, o Conselho Monetário Nacional (CMN), o Conselho Nacional de Seguros Privados (CNSP) e o Conselho de Gestão da Previdência Complementar (CGPC). Dentre esses três órgãos, nos deteremos a conhecer em maiores detalhes apenas o primeiro, dada sua maior relevância para o estudo em questão. 
Em resumo, temos que o SFN apresenta como instituto supremo o CMN, o qual atua regulando as instituições financeiras presentes no país, ditando as normas para funcionamento tanto do BACEN quanto da CVM, que por sua vez tem subordinados a ela a Bolsa de Mercadorias e Futuros e a Bolsas de Valores.

\section{Crises financeiras}

Wolf (2009) destaca que nas décadas de 1970, 1980 e 1990, as crises financeiras sempre ocorreram após períodos nos quais predominaram volumosos fluxos líquidos de capital para as economias de mercados emergentes. Na década de 2000, por sua vez, o retro citado economista, explica que o desejo dos investidores privados de aplicar dinheiro mais uma vez em muitos desses países levou as economias de mercado emergentes a promover intervenções cambiais de grande escala e a acumular reservas estrangeiras.

Continua o britânico, economista e jornalista do Financial Times, afirmando que até o terceiro trimestre de 2007, nenhuma crise de vulto nos mercados emergentes havia ocorrido desde 2001 (quando do calote argentino), enquanto a última onda global de crise a afetar as economias emergentes ocorrera entre 1997 e princípios de 1999. "Isso poderia sugerir que a economia mundial tornara-se estável", relata Wolf (2009). Diante dessa dinâmica, o referido economista suscita duas questões: "Será que esse padrão de fluxos líquidos de capital, em âmbito global, é sustentável? E será que esse fluxo de capital dos países pobres para os países ricos é desejável?"

A crise do próprio sistema de regulação, definida por Boyer apud Chesnais como designando as situações em que "os mecanismos associados à regulação em vigor revelamse incapazes de reverter os encadeamentos conjunturais desfavoráveis, mesmo que, pelo menos inicialmente, o regime de acumulação seja viável", refere-se à situação que se cristaliza por volta de 1978-1979, durante o segundo choque do petróleo.

A internacionalização do capital parece ter desempenhado um papel importante na "incapacidade em que os mecanismos associados à regulação em vigor" demonstram, "de reverter os encadeamentos conjunturais desfavoráveis" (CHESNAIS, 1996).

A economia mundial passou por vários sobressaltos ou choques monetários e financeiros, cuja configuração foi complexa e variável e cuja frequiência parece ter-se acelerado. São os "acidentes financeiros disparatados e recorrentes", nascidos da globalização financeira e "colocando problemas graves, por suas incidências globais sobre a economia mundial", às quais M. Aglietta já dedicou atenção (1995, p. 70).

A conjuntura mundial dos anos 90 apresenta as características de uma depressão econômica longa (no sentido de Schumpeter, em seu trabalho clássico sobre os ciclos econômicos). Para Sweezy apud Chesnais, nesta década as tendências são claramente estagnacionistas, como nos anos 30. Mesmo que a retomada, tantas vezes anunciada, viesse a se concretizar, é provável que não seria mais do que parte de uma ondulação, sobre o fundo dessa depressão longa.

Chesnais (1996) sustenta a hipótese de que as formas assumidas pela mundialização dos grupos industriais, dos grandes grupos de distribuição (comércio atacadista e varejista) e do capital monetário exercem, de modo estrutural, um efeito depressivo sobre a acumulação. Continua afirmando que esse efeito é global, embora seu impacto sobre os 
países e conjuntos "regionais" permaneça diferenciado, de modo que o caráter mundial da depressão não comportou uma sincronização de conjunturas. As relações mais importantes são apresentadas na figura a seguir:

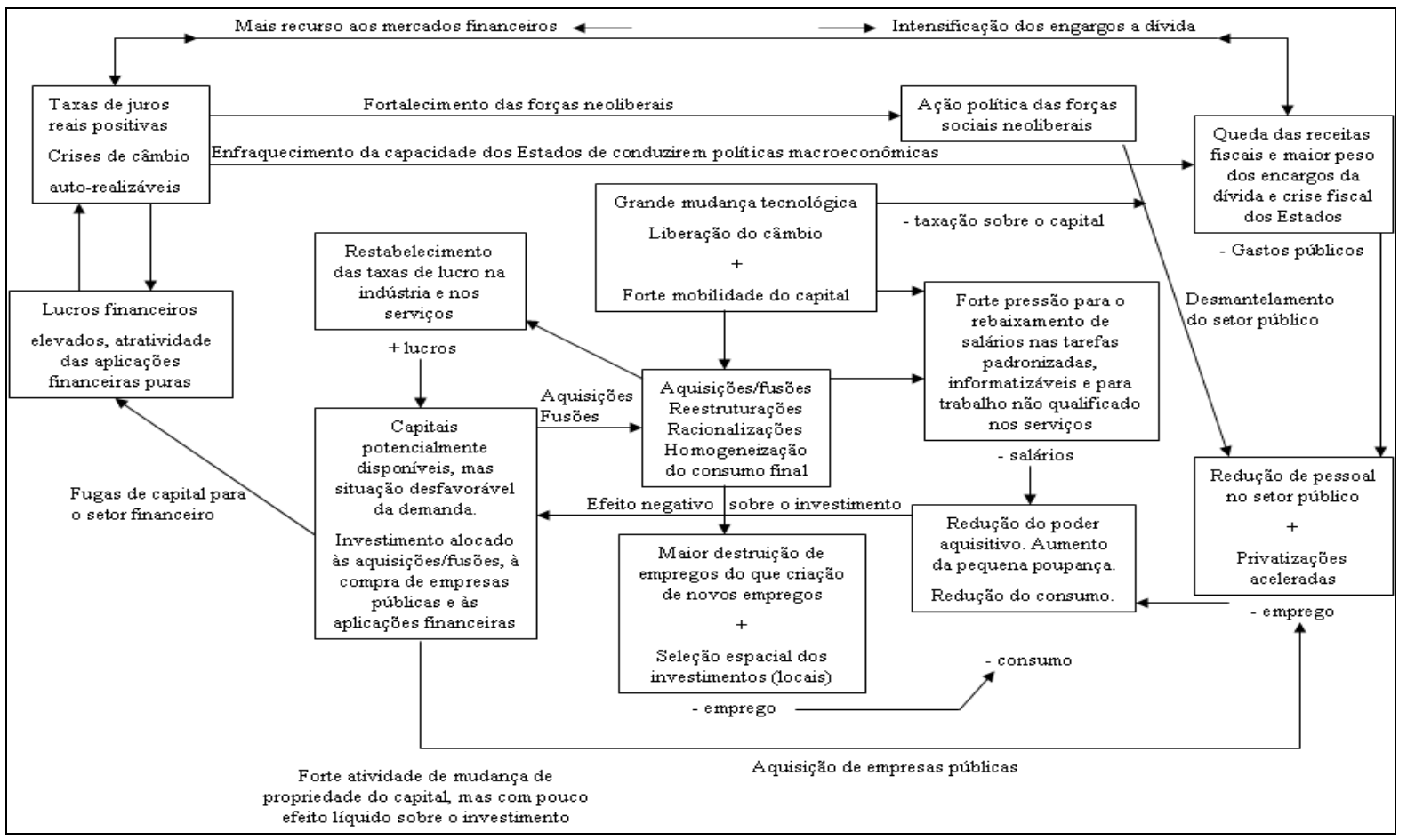

Figura 1 - Encadeamentos cumulativos "viciosos" da mundialização Fonte: Chesnais, 1996, p. 305

Para finalizar, é interessante observar o posicionamento de Wolf (2009) quanto à necessidade da instauração de uma reforma global. Defende o britânico que as reformas mais importantes devem se situar no nível de país, principalmente pelo desenvolvimento de mercados em moeda nacional, do qual estrangeiros possam participar. Quanto às mudanças em nível internacional, considera quatro mais importantes: a perspectiva de um sistema monetário global; a reforma do sistema financeiro global; a reforma das instituições financeiras internacionais e, mormente, do Fundo Monetário Internacional (FMI); e, por último, a reforma de grupos informais, como o Grupo dos Sete países de alta renda (G-7) e o Grupo dos Vinte (G-20), que inclui os principais países emergentes e outros países de alta renda.

\section{Crise americana}

Os fluxos líquidos de capital passaram a correr do resto do mundo para uns poucos países de alta renda confiáveis e, acima de tudo, para os Estados Unidos, que se converteu na superpotência dos devedores globais. A ascensão dos EUA como credor gigantesco efetivamente gerou certo nível de bem-vinda estabilidade econômica e financeira. $\mathrm{Na}$ qualidade de maior economia do mundo, detentora da moeda mais importante do globo, os EUA são muito mais capazes que qualquer outro país ou até que alguns grupos de países, de captar grandes empréstimos no exterior. Porém, a contrapartida interna da tomada de empréstimos externos acabou gerando o que veio e revelar-se um aumento insustentável do endividamento das famílias. Essa situação redundou na crise do "subprime" e eclodiu 
como choque financeiro cujas ondas começaram a varrer os países de alta renda em 2007. (WOLF, 2009)

O grande diferencial da crise americana, em relação a crises financeiras anteriores, é produto do aprofundamento da globalização da economia, o qual torna possível a bancos e instituições financeiras dispersarem os riscos de prejuízos, por meio de emissão de títulos para serem negociados. O problema é que se alguém deixa de honrar suas dívidas, esses títulos passam a não ter valor de mercado (títulos podres) e uma série de investidores pode sair perdendo e ainda realizar transações, em vistas a não perder mais ainda ou a reaver o que perdeu, as quais são notabilizadas em todo o mundo, em tempo real praticamente, gerando com isso muitas oscilações no mercado de valores, o que pode repercutir nos diversos setores da economia mundial.

Para finalizar a análise sobre a emergência da Crise Americana, é interessante observar que Krugman (2009) chama a atenção para o posicionamento de economistas, os quais chegaram a defender que o mundo não teria mais graves problemas econômicos, como se os ciclos econômicos tivessem chegado ao fim. Chama a atenção, o professor americano, para as alegações de alguns economistas, como Robert Lucas, em 2003, de que os ciclos econômicos, a alternância irregular de recessões e expansões com que convivemos há pelo menos um século e meio haviam se "amansado" e Bem Bernanke, que em 2004 argumentou num discurso intitulado "A Grande Moderação", que a política macroeconômica moderna havia resolvido o problema dos ciclos econômicos.

Diante da Crise Americana, que demonstra veementemente a invalidez dessas teorias, KRUGMAN (2009) defende que os pontos mais importantes a serem compreendidos são como a catástrofe pode-se repetir, como as vítimas podem recuperar-se e como podemos evitar que aconteça outra vez. O objetivo, para ele, é desenvolver a teoria do caso, ou seja, definir como pensar sobre o tema.

\section{Globalização atual e processos de integração entre empresas}

Verifica-se nos últimos anos uma tendência de empresas optarem por processos de gestão que integrem as atividades operacionais de duas ou mais organizações, no intuito de se fortalecerem e tornarem-se mais sólidas no setor do mercado no qual atuem.

Na realidade do sistema bancário, de acordo com Schulman, cada vez mais no mundo haverá menos bancos, bancos maiores, e as pessoas irão se ligar apenas eletronicamente. Daqui a pouco, não vai ter mais nenhum papel.

A despeito da importância que fusões e aquisições bancárias têm adquirido, não só no Brasil como no mundo, é escassa a reflexão nacional sobre o tema. A discussão no país está excessivamente centrada sobre um aspecto institucional específico, qual seja, o de que órgão deve ser responsável pelo julgamento de atos de concentração horizontal e de atos anticompetitivos neste setor, afirmam Nakane e Alencar (2004).

Acompanhando esse cenário, as ações de muitos bancos seguem no mesmo sentido, marcadas por mecanismos tais como aquisições e fusões. Nesse contexto, no corrente ano de 2008, marcado pela crise financeira iniciada nos Estados Unidos da América e que repercute em todo o mundo, a fusão do Itaú com Unibanco cria o primeiro banco brasileiro 
com porte global, precipitando, assim, uma nova onda de consolidação no sistema financeiro do país.

No mercado brasileiro, as previsões são de que o novo banco passará a ocupar uma liderança invejada pelo Banco do Brasil e por seus principais concorrentes privados, Bradesco e Santander. Quando se comparam ativos financeiros, o único que se aproxima é o Banco do Brasil - e somente se ele concretizar as compras da Nossa Caixa e do Banco Votorantim, dadas como certas pelo mercado.

Já na esfera internacional, a fusão do Itaú com Unibanco cria o primeiro banco brasileiro com porte global, e, juntos, formam o $16^{\circ}$ maior banco do mundo em valor de mercado, acima do espanhol BBVA e do suíço Credit Suisse, como se pode observar através da tabela abaixo:

Tabela 1 - Instituições bancárias com maior valor de mercado (US\$ bilhões)

\begin{tabular}{c|c|c}
\hline 1 & ICBC (China) & 176 \\
\hline 2 & JPMORGAN CHASE (EUA) & 152 \\
\hline 3 & HSBC (Inglaterra) & 147 \\
\hline 4 & CHINA CONSTRUCTION (China) & 122 \\
\hline 5 & BANK OF AMERICA (EUA) & 118 \\
\hline 6 & WELLS FARGO (EUA) & 112 \\
\hline 7 & BANK OF CHINA (China) & 101 \\
\hline 8 & CITI (EUA) & 76 \\
\hline 9 & SANTANDER (Espanha) & 67 \\
\hline 10 & MITSUBISHI UFJ (Japão) & 66 \\
\hline 11 & BNP PARIBAS (França) & 64 \\
\hline 12 & US BANCORP (EUA) & 53 \\
\hline 13 & ROYAL BANK OF CANADA (Canadá) & 53 \\
\hline 14 & UBS (Suíça) & 47 \\
\hline 15 & INTESA SANPAOLO (Itália) & 46 \\
\hline 16 & ITAÚ UNIBANCO (Brasil) & 45 \\
\hline
\end{tabular}

Fonte: Adaptado pela revista EXAME de Bloomberg e Reuters, (2008)

\section{O Brasil diante da atual crise global}

Tavares (2009) afirma que as reservas de quase U\$200 bilhões tem permitido inclusive financiar as exportações e rolar parte da dívida externa do setor privado nacional; estando, nosso país, entre os demais latinos, na melhor situação na América Latina, dadas as elevadas taxas de juros que vinha praticando e a maior carga tributária de toda região, o que lhe permite maiores incentivos pelos meios tradicionais). Sua dívida interna é a mais baixa das últimas décadas e deve continuar baixa se as taxas de juros continuarem caindo acentuadamente durante o ano, dadas as expectativas favoráveis de inflação e câmbio, 
prevê. Além desses pontos, destaca que o Brasil possui um sistema financeiro hígido, com altos lucros e que representa cerca de $2 / 3$ dos negócios de toda a região.

Por fim, dentre outras observações, ela diz que o Brasil é auto-suficiente em energia e alimentos, possuidor de programas sociais compensatórios para cerca de dez milhões de famílias, detentor do mercado interno mais forte da América latina e que seu coeficiente de dependência do comércio exterior encontra-se entre os menores do mundo.

Apesar destas condições favoráveis, explicita que o Brasil, assim como os demais países latinos, não ficou imune à crise. Lembra que houve uma forte retração da produção industrial no último trimestre de 2008, a qual se manteve até o final do primeiro trimestre de 2009 - em particular nos setores exportadores; e que a arrecadação fiscal caiu fortemente, atingindo União, Estados e Municípios.

A crise chegou ao Brasil na forma de uma súbita interrupção da concessão de crédito à economia. Desse modo, as primeiras medidas adotadas pelo Governo foram voltadas para o mercado de crédito e de moeda, e posteriormente para o campo fiscal.

O crédito, no Brasil, caracteriza-se principalmente pela concentração bancária e por operações de curto prazo agregadas a custos bastante elevados, cujas taxas reais de juros ultrapassam a expansão real do PIB, de acordo com especialistas da área.

De meados de setembro até o final do último trimestre de 2008, o Brasil esteve entre as economias que sofreram a maior depreciação cambial e as maiores perdas na bolsa de valores, de acordo com análises da CACFE.

Tendo como referencial essa constatação, vejamos o gráfico abaixo:

Gráfico 1 - Evolução do crédito sobre o PIB (jun/02 a mar/09)

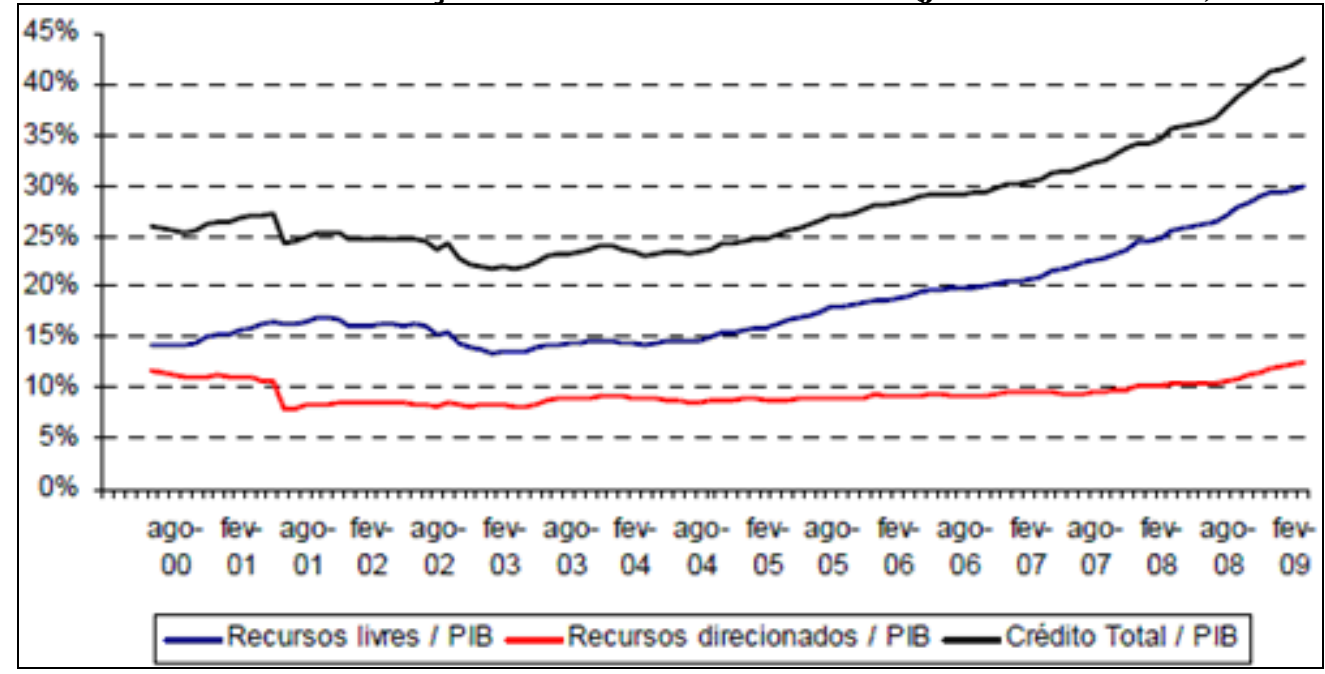

Fonte: BACEN (2009)

Verificamos uma tendência de expansão do crédito ofertado. $\mathrm{O}$ volume do crédito total, por exemplo, experimentou uma considerável expansão - passando de cerca de $26 \%$, em junho de 2000, para mais de 42\%, em março de 2009. Os analistas da CACFE, conferem esse aumento, em boa parte, à expansão das operações livres, cuja proporção em relação ao PIB dobrou entre agosto de 2004 e março de 2009. 
Depois dessa análise, vejamos as consequiências da quebra do Lehman Brothers para o sistema brasileiro de créditos. Autoridades monetárias brasileiras afirmam que a quebra do supracitado banco americano, ao afetar o sistema de crédito internacional, resultou numa concomitante retração de concessão de crédito doméstico. Desde junho de 2008, contudo, conforme releva o gráfico seguinte, apresentado pelo presidente do Banco Central, em audiência pública de 25 de março de 2009, o crédito vinha sofrendo esse processo de contração.

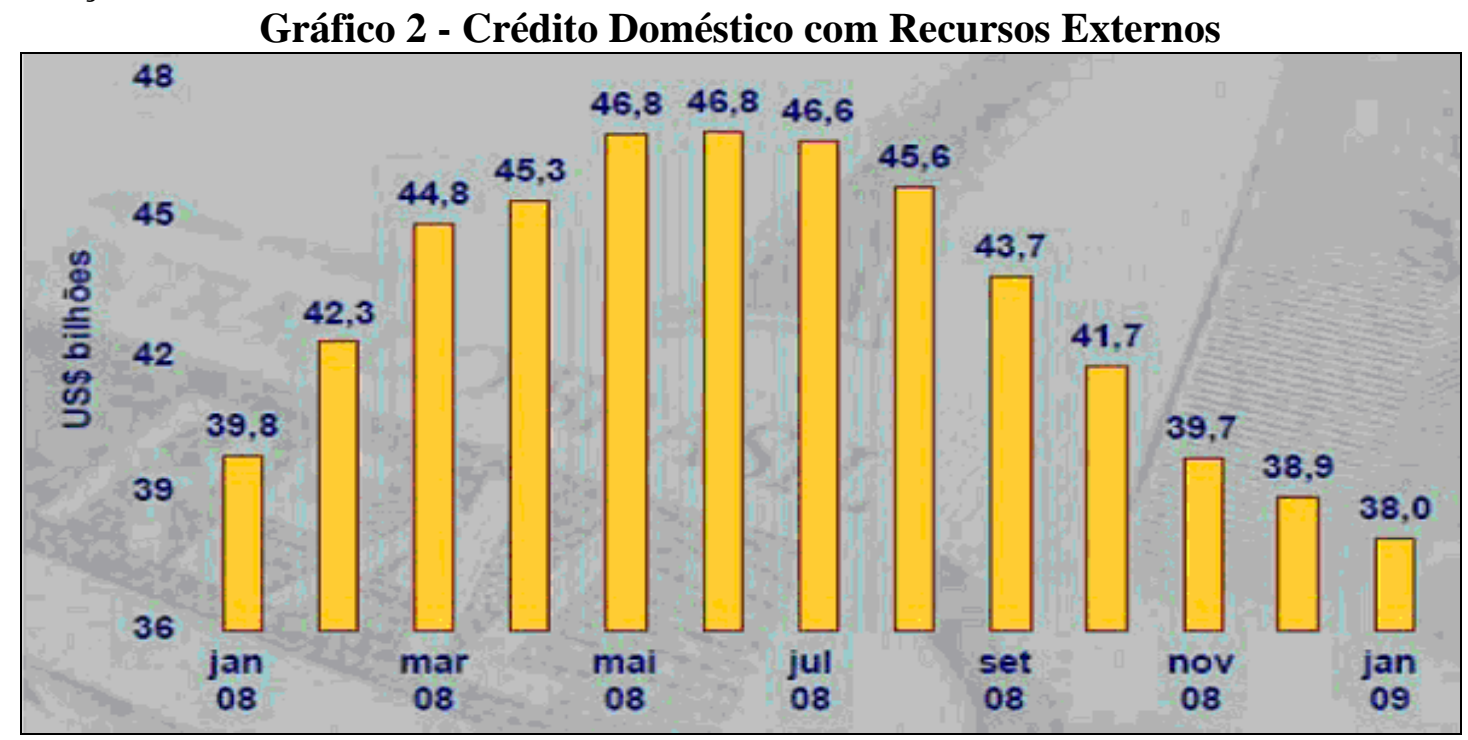

Fonte: Banco Central (2009)

$\mathrm{O}$ relatório da CACFE observa que, "paradoxalmente, o que sempre foi apontado como uma grave deformação da economia brasileira - a taxa básica real de juros (SELIC) das mais altas do mundo - tornou-se uma vantagem ímpar, relativamente a outras economias". Assim, sem pressões inflacionárias e diante de um novo cenário de queda acentuada dos preços das commodities, o Banco Central resolveu reduzir continuamente a taxa básica de juros.

O Senado Federal cria a Comissão de Acompanhamento da Crise Financeira e da Empregabilidade (CACFE), com o intuito de reunir informações acerca dos desdobramentos da crise econômica e financeira, para ter então condições de atuar na busca de soluções para minimizar seus efeitos no Brasil, por meio de estudos, análises técnicas e medidas criativas, "com respaldo dos diversos segmentos envolvidos, de acordo com a vocação do Parlamento de ser o interlocutor da sociedade, do mercado e do governo".

Além da criação da referida Comissão para tratar de assunto ligados à crise internacional, o Conselho de Desenvolvimento Econômico e Social (CDES), que corresponde a um órgão consultivo da Presidência da República, também participa do "movimento" contra os possíveis efeitos nocivos oriundos de tal crise para o Brasil. Nessa direção, o CDES promoveu um grande debate sobre o desenvolvimento do nosso país em meio à crise econômica internacional, na primeira reunião plenária de 2009, nos dias 5 e 6 de março, em Brasília, através do Seminário Internacional sobre Desenvolvimento. Em pauta, os desafios do Estado diante da crise, a regulação do sistema financeiro e o novo papel das instituições financeiras. 
Com relação as mudanças verificadas no setor da indústria, antes de analisar a tendência da produção industrial, conheçamos o contexto internacional. De 2005 até 2008 a tendência se manteve praticamente estável, com oscilações semelhantes. Contudo, a partir de 2008 observa-se um declínio bastante acentuado dessa produção industrial global, como podemos observar no gráfico abaixo:

Gráfico 3 - Tendência da Produção Industrial Global

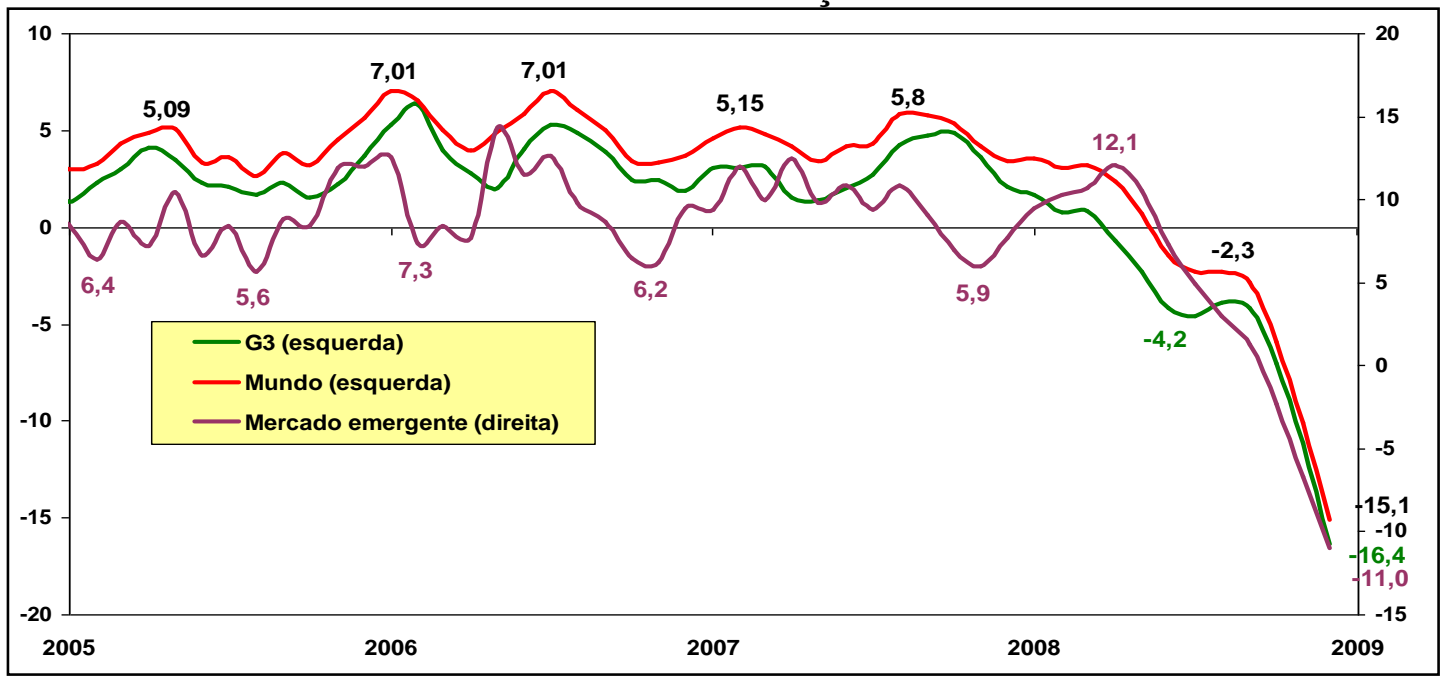

Fonte: DEPEC (2009)

O Brasil, por sua vez, teve na indústria, de acordo com analistas estudiosos do impacto da crise no Brasil, de longe o setor mais afetado da economia, apresentando uma intensa queda de produção e, o pior, do emprego. Podemos observar tal ocorrência por meio da visualização dos valores anuais de crescimento industrial. Verifica-se que, mesmo tendo oscilado bastante, desde 1999 não havia crescimento negativo do setor.

Vejamos:

Gráfico 4 - Crescimento da Produção Industrial do Brasil

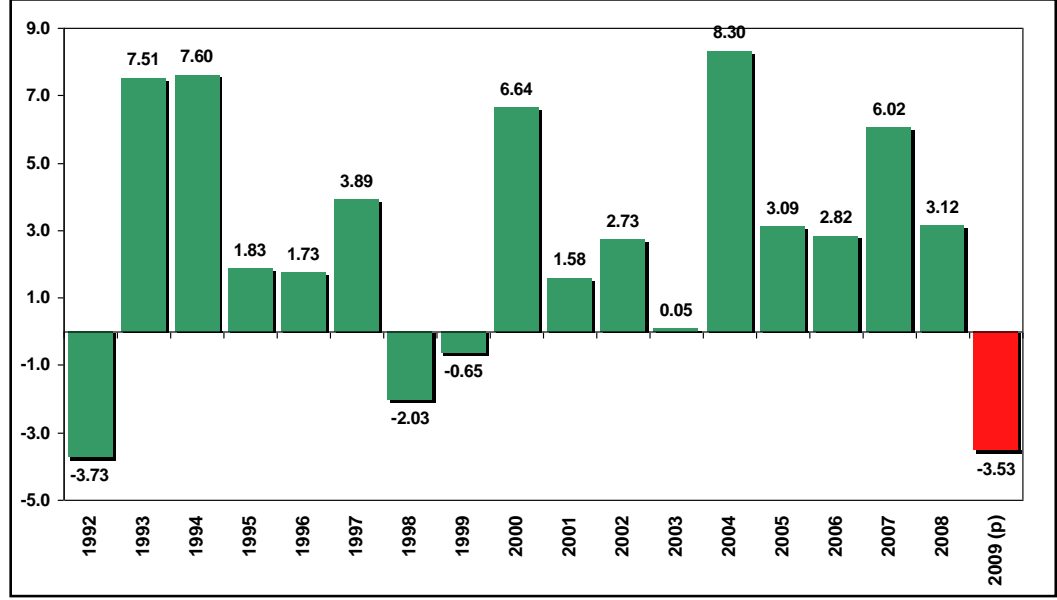

Fonte: IBGE/ Elaboração: Bradesco (2009)

Diante de uma projeção de crescimento negativo para 2009, o governo precisou tomar medidas. Para fomentar a indústria, portanto, o governo, revela o relatório da Comissão do 
Senado, reagiu expandindo a oferta de crédito para giro e para fomento ao investimento pelos bancos públicos, além de conceder uma série de incentivos fiscais.

Quanto às alterações na política tributária decorrentes do impacto da crise na economia nacional, sem dúvidas, o caso de maior repercussão, amplamente noticiado pela mídia, foi a redução do IPI da indústria automobilística e, em segundo lugar, da indústria da construção civil - resultando em preços de materiais de construção mais baixos, e, mais recentemente, dos eletrodomésticos da chamada linha branca.

As contas externas brasileiras, nesse contexto de crise mundial, sofreram os mesmos efeitos de todos outros países, em razão da profunda retração do comércio internacional. As exportações brasileiras sofreram pelo lado dos produtos primários, com a contenção de preços de commodities e, pelo lado das manufaturas, com a retração das outras economias, não apenas dos países ricos, mas também dos vizinhos latinos, principal destino de nossos bens industriais. (CACFE, 2009)

A respeito do comércio exterior, vejamos os dados reais consolidados até maio de 2009, a partir de valores fornecidos pelo Ministério de Desenvolvimento, Indústria e Comércio Exterior (MDIC).

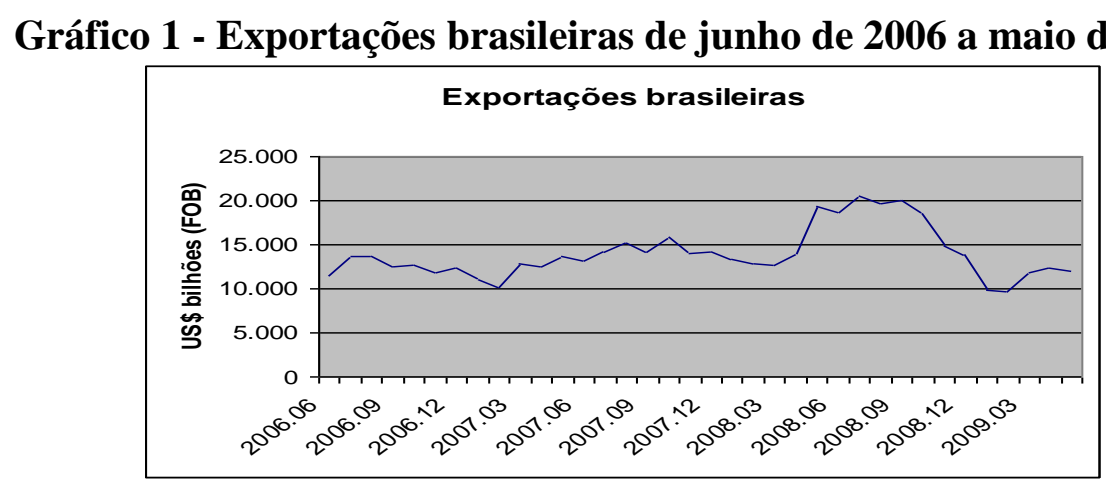

Fonte: MDIC/ Elaborado pela pesquisadora (2009)

O gráfico mostra que a tendência das exportações, no primeiro semestre de 2008 , foi a de se manterem em patamares bastante consideráveis, oscilando em torno de 20 milhões de dólares. Em agosto, entretanto, quando as exportações atingem o nível de 20.017 milhões de dólares observa-se que começam a declinar até janeiro de 2009, quando chegam ao valor de 9.500 milhões de dólares.

Conclui-se, com isso, que o peso da Crise Internacional afetou as negociações comerciais mundiais. O Brasil, entretanto, vem respondendo a ela, por meio de várias medidas econômicas, e, como podemos depreender pela análise do gráfico, elas já estão surtindo efeito, pois as exportações a apresentar uma tendência crescente, encontram-se em maio, em torno de 12.000 milhões de dólares. Assim, partimos à análise das importações realizadas pelo Brasil.

Vejamos o gráfico seguinte: 


\section{Gráfico 2 - Importações brasileiras de junho de 2006 a maio de 2009.}

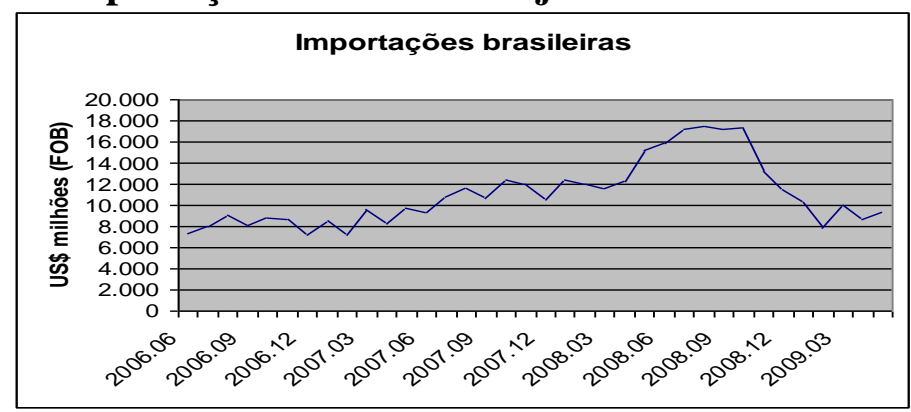

Fonte: MDIC/ Elaborado pela pesquisadora (2009)

Podemos ver que as importações apresentam certa semelhança com a tendência das exportações. Até outubro de 2008 cresceram, chegando aos 17.300 milhões de dólares, para decair consideravelmente, atingindo o patamar de 7.800 milhões de dólares em fevereiro de 2009. Uma queda bastante considerável, de mais de 50\%. No início desse período, ou seja, no último trimestre de 2008, podemos associar a queda aos entraves internacionais às negociações internacionais, em 2009, contudo, um fator bastante importante, para contribuir com níveis mais baixos de importações, tem sido a política tributária adotada pelo Governo, representado principalmente pela redução do IPI, o que tem estimulado bastante o mercado interno nacional.

Depois dessas análises relativas ao Comércio Internacional, vejamos o que recomenda o Ministro do Desenvolvimento, Indústria e Comércio Exterior, Miguel Jorge, em capítulo do livro "Na Crise Global, como ser o melhor dos Brics", quanto ao desenvolvimento produtivo brasileiro para se evitar a volta da vulnerabilidade externa.

Jorge (2009) inicia sua explanação afirmando que a idéia de que o desempenho de longo prazo do balanço de pagamentos pode representar uma restrição importante ao crescimento dos países em desenvolvimento, em particular o Brasil. O debate sobre restrição externa ao crescimento brasileiro, prossegue o Ministro, foi bastante intenso durante a segunda metade dos anos 90, quando tivemos elevados e persistentes déficits em transações correntes. "As recorrentes crises internacionais do período também serviram para colocar em evidência a vulnerabilidade da economia brasileira aos choques externos", acrescenta.

Afirma, contudo, que muito mudou daquela época para hoje. Assim, pergunta até que ponto as mudanças pelas quais passou a economia nacional nos últimos anos conseguiram afastar ou não o problema da vulnerabilidade externa.

Por fim, nesse contexto econômico, é importante tratar da Política de Desenvolvimento Produtivo (PDP), lançada pelo Governo Federal em maio de 2008. Jorge (2009) acredita que esse programa é de fundamental importância para garantir a sustentabilidade das transações externas brasileiras no longo prazo. O papel dessa política, destaca o ministro, é fomentar o desenvolvimento da produção nacional, com o objetivo de tornar a indústria brasileira mais competitiva e tecnologicamente mais avançada no longo prazo. "Nesse sentido, ampliar as exportações brasileiras e nossa participação no Comércio Internacional é um dos objetivos centrais da PDP e da Estratégia Brasileira de Exportações lançada pelo MDIC", acentua Jorge (2009). 


\section{CONSIDERAÇÕES FINAIS}

A economia moderna é muito dinâmica, podendo ser enxergada, guardadas as devidas proporções, por meio de uma simples analogia, dizendo que ela seria a face oposta e indissociável do sistema financeiro, o qual pode ser, a grosso modo, identificado por uma constante e infindável oscilação randômica de valores monetários e de títulos de crédito, assim como a cara e a coroa constituem as faces da mesma moeda.

O sistema financeiro, marcado por transferências de montantes, que muitas vezes ainda nem existem, caracteriza-se por sua intangibilidade. A economia, em contraposição, identifica-se por uma indubitável tangibilidade, já que representa, de fato, a circulação e oferta de produtos e serviços, resultantes da conversão de valores transacionados eletronicamente em termos concretos e paupáveis, que se destinam a saciar os desejos e necessidades do homem.

Depois dessa prévia apresentação ao campo vasto e complexo formado pelo sistema financeiro e pela economia real, verificamos que há atores que sempre entram em cena, mesmo que com certa irregularidade, o que não significa que eles não se façam notar. Falo das crises financeiras, como a Crise Americana de 1929, derrocada com a quebra da bolsa de Nova Iorque; as Crises da década de 70, pós-choques do petróleo em 1974 e 1979; as crises financeiras da América Latina da década de 80, marcadas principalmente pela manutenção de elevadas taxas inflacionárias; a Crise do Capitalismo da década de 90, marcada notadamente pela crise cambial mexicana de 1994, pelas crises na Argentina, na Ásia, no Japão e no Brasil, e mesmo da última crise do petróleo, em 2008, quando os preços subiram mais que o dobro no primeiro semestre.

A presença de crises, como podemos verificar, são comuns e corriqueiras no Sistema Capitalista, assim como as recessões e intervalos de crescimento são sintomas normais do ciclo econômico.

O que se quer dizer com isso, é que os países devem estar sempre alertas em relação aos acontecimentos mundiais, para que possam se precaver da forma mais eficiente possível daqueles não desejáveis e combater os malefícios do sistema financeiro global.

A Crise Financeira dos EUA teve início com a crise do sistema imobiliário, que propagou pelo mundo "promessas de pagamentos", muitos títulos sem valor nenhum, já que dependiam honradez das obrigações contraídas pelos americanos. Assim, as especulações fervilharam e muitos temerosos, de perder ainda mais dinheiro, retiraram seus investimentos das principais bolsas de valores do mundo. Com isso bancos quebraram e economias entraram em recessão e algumas em depressão pelo mundo afora.

O Brasil nesse contexto se mostrou preparado, sendo detentor de uma reserva monetária da ordem de 200 bilhões de dólares; tendo suas instituições financeiras fortalecidas, principalmente pela fusão do Itaú com o Unibanco, que fez com que o país tenha agora um banco de proporções mundiais; apresentando o Governo Federal, em 2008, a Política de Desenvolvimento Produtivo e, por fim, tendo o MDIC, em 2009, lançado a Estratégia Brasileira de Exportações.

O Brasil entra na crise devido à diminuição do crédito internacional. Partindo desse fator preponderante, parte para a adoção de políticas econômicas que visem primordialmente 
aumentar o crédito nacional, diminuir o spread bancário e aquecer a economia nacional, por meio da política tributária de redução e isenção do IPI.

O país não foi mais prejudicado porque representa apenas $1 \%$ das negociações internacionais envolvidas em comércio exterior, e, além disso, pôde se utilizar inicialmente de uma política monetária voltada para redução das taxas de juros, como é exemplo a TJLP, que baixou no mês de junho de 2009 para 6\%. Muitos países não puderam se utilizar de tal medida, visto que já praticava taxas de juros muito pequenas, passando imediatamente a adotar políticas fiscais, que resultaram numa diminuição de receita ou aumento de despesa, e acabaram por agravar ainda mais a situação financeira e econômica em tais nações.

Por fim, conclui-se que as crises sempre se farão presentes no Sistema Capitalista, e, por isso, é necessário que os países além de se manterem em alerta por meio de Políticas Econômicas mais responsáveis, se unam na busca de uma regulação internacional econômica mais eficiente e confiável, visto que, atualmente, o FMI representa os interesses dos ricos, pois eles detêm a maioria dos votos. Mesmo assim, não se deve pensar que as crises não mais existirão, mesmo que se sucedem períodos de calmaria, pois como diz o ditado "antes da tempestade vem a bonança".

\section{REFERÊNCIAS BIBLIOGRÁFICAS}

1. ANGELO, Ivan. Febraban: 40 anos de participação. São Paulo: DBA Artes Gráficas, 2007. BRASIL.

2. BRASIL. Constituição Federal. Brasília: Senado Federal, 1988.

3. CHESNAIS, François. A mundialização do capital. São Paulo: Xamã, 1996.

4. CONFEDERAÇÃO NACIONAL DA INDÚSTRIA. Pesquisa CNI: crise afetou 7 em cada 10 empresas exportadoras. Brasília, 28 de maio de 2009. Disponível em: <http://www.cni.org.br/portal/main.jsp?lumPageId=4028809713F827B10113F884BF5 92E30\&lumI=servicocorporativo.agenciaindustria.detAgenciaIndustria\&itemId=8A901 5D0216AAFB5012188741BAC01AC\#Conteudo>Acesso em 28 de junho de 2009.

5. CHACEL, Julian M. Reflexão sobre o sistema bancário e os juros. Disponível em: <http://www.caringi.com.br/aberj/reflexao.htm> Acesso em 9 de dezembro de 2008

6. CRESPO, Antônio Arnot. Estatística Fácil. 18. ed. São Paulo: Saraiva, 2002.

7. DE MENDONÇA, Ana Rosa Ribeiro e DE ANDRADE, Rogério Pereira. Regulação bancária e dinâmica financeira: evolução e perspectivas a partir dos acordos de Basiléia. Campinas, SP: Unicamp, 2006.

8. DIEESE. A valorização do real e as negociações coletivas. Disponível em: <http://www.dieese.org.br/esp/cambio/notatecnica03_cambio.pdf> Acesso em dezembro de 2007.

9. Política de Desenvolvimento Produtivo: Nova Política Industrial do Governo. Nota Técnica n67, 2008. Disponível em: <http://www.dieese.org.br/notatecnica/notaTec67PoliticaDesenvolvimento.pdf> Acesso em 29 de junho de 2009.

10. GIL, Antônio Carlos. Como elaborar projetos de pesquisa. São Paulo: Atlas, 2002. 
11. GITMAN, Lawrence Jeffrey. Princípios de administração financeira. $10^{\mathrm{a}}$ ed. São Paulo: Pearson Addison Wesley, 2004.

12. JUNIOR, Januário Hostin. Fusões e Aquisições. Disponível em: $<$ http://empreendedor.uol.com.br/?secao $=$ Noticias\&categoria $=137 \&$ codigo $=9727>$ Acesso em 07 de dezembro de 2008.

13. KRUGMAN, Paul R. A crise de 2008 e a economia de depressão. Rio de Janeiro: Elsevier. 2009.

14. MILONE, Giuseppe. Estatística Geral e Aplicada. São Paulo: Pioneira, Thomson Learning, 2004.

15. NAKANE, Márcio I. e ALENCAR, Leonardo S. Análise de fusões e aquisições horizontais no setor bancário: uma reflexão a partir da experiência internacional. Departamento de estudos e pesquisas, Banco Central do Brasil, 2004.

16. SENADO FEDERAL. Relatório parcial da CACFE. Brasília, junho de 2009. Disponível em: <http://www.senado.gov.br/sf/atividade/materia/getPDF.asp?t=60394> Acesso em: 28 de junho de 2009.

17. SIQUEIRA, Alexis Cavicchini Teixeira. A história dos bancos no Brasil: das casas bancárias aos conglomerados financeiros. Rio de Janeiro: COP Editora LTDA, 2007

18. TAVARES, Maria da Conceição. A crise financeira: duração e impacto no Brasil e na AL. Disponível em: <http://www.cartamaior.com.br/templates/materiaMostrar.cfm?materia_id=16019> Acesso em: 28 de junho de 2009.

19. TOSCANO JÚNIOR, Luis Carlos. Guia de referência para o mercado financeiro. São Paulo: El-Edições Inteligentes, 2004.

20. VELLOSO, João Paulo dos Reis (Org) e DE ALBUQUERQUE, Roberto Cavalcanti (Org). Na crise global, como ser o melhor dos BRICs. Rio de Janeiro: Elsevier, 2009.

21. WOLF, Martin. A reconstrução do sistema financeiro global. Rio de Janeiro: Elsevier, 2009. 